\title{
BMJ Global Health Identifying knowledge needed to improve surgical care in Southern Africa using a theory of change approach
}

To cite: Breedt DS, Odland ML, Bakanisi B, et al. Identifying knowledge needed to improve surgical care in Southern Africa using a theory of change approach. BMJ Global Health 2021;6:e005629. doi:10.1136/ bmjgh-2021-005629

Handling editor Seye Abimbola

- Additional supplemental material is published online only. To view, please visit the journal online (http://dx.doi.org/10. 1136/bmjgh-2021-005629)

DSB and MLO contributed equally.

$\mathrm{KC}$ and JID contributed equally.

DSB and MLO are joint first authors.

$\mathrm{KC}$ and JID are joint senior authors.

Received 7 March 2021 Accepted 6 May 2021

Check for updates

(C) Author(s) (or their employer(s)) 2021. Re-use permitted under CC BY-NC. No commercial re-use. See rights and permissions. Published by BMJ.

For numbered affiliations see end of article.

Correspondence to Dr Maria Lisa Odland; m.l.odland@bham.ac.uk

\section{ABSTRACT}

Surgical healthcare has been prioritised in the Southern African Development Community (SADC), a regional intergovernmental entity promoting equitable and sustainable economic growth and socioeconomic development. However challenges remain in translating political prioritisation into effective and equitable surgical healthcare. The AfroSurg Collaborative (AfroSurg) includes clinicians, public health professionals and social scientists from six SADC countries; it was created to identify context-specific, critical areas where research is needed to inform evidence-grounded policy and implementation. In January 2020, 38 AfroSurg members participated in a theory of change (ToC) workshop to agree on a vision: 'An African-led, regional network to enable evidence-based, context-specific, safe surgical care, which is accessible, timely, and affordable for all, capturing the spirit of Ubuntu', and to identify necessary policy and servicedelivery knowledge needs to achieve this vision. $A$ unified ToC map was created, and a Delphi survey was conducted to rank the top five priority knowledge needs. In total, 45 knowledge needs were identified; the top five priority areas included (1) mapping of available surgical services, resources and providers; (2) quantifying the burden of surgical disease; (3) identifying the appropriate number of trainees; (4) identifying the type of information that should be collected to inform service planning; and (5) identifying effective strategies that encourage geographical retention of practitioners. Of the top five knowledge needs, four were policy-related, suggesting a dearth of much-needed information to develop regional, evidenced-based surgical policies. The findings from this workshop provide a roadmap to drive locally led research and create a collaborative network for implementing research and interventions. This process could inform discussions in other low-resource settings and enable more evidencedbased surgical policy and service delivery across the SADC countries and beyond.

'Ubuntu translates to 'I am because we are' and captures a philosophy of humanity. It is a Nguni Bantu term.
Summary box

While the Southern African Development Community (SADC) has acknowledged that surgery should be a part of universal health coverage, the lack of context-specific knowledge limits the translation of this political prioritisation into effective health programmes that improve surgical healthcare at a population level.

- The AfroSurg Collaborative (AfroSurg), a new network consisting of key stakeholders, connected to the field of surgery, from six countries in sub-Saharan Africa, identified key areas in service delivery and policy where more knowledge is needed through a theory of change approach.

- The five priority knowledge needs included (1) mapping of available surgical services, resources and providers; (2) quantifying the burden of surgical disease (3) identifying the appropriate number of trainees; (4) identifying the type of information that should be collected to inform service planning; and (5) identifying effective strategies to encourage geographical retention of practitioners.

- There is a common vision for improving surgical services across the SADC nations that can inform a cohesive approach across the region, and knowledge needs identified by AfroSurg collaborators should be used to collect information that will inform the design of these services.

\section{INTRODUCTION}

An estimated $90 \%$ of people in sub-Saharan Africa (SSA) lack access to safe, timely and affordable surgical care, despite evidence that it would enhance welfare and promote economic growth and sustainable development. ${ }^{12}$ Poor surgical outcomes in SSA suggest health systems are underperforming. 
There is a need to strengthen health systems by better understanding and systematically exploring through rigorous research the reasons responsible for suboptimal surgical healthcare in the region. ${ }^{3}$ SSA has the highest number of preventable deaths and the largest proportion of disability-adjusted life years (DALYs) globally. Scaling up effective coverage of surgical care in the region will help avert millions of deaths and DALYs. ${ }^{14}$ However, substantial need for country-specific local knowledge limits the translation of political priorities into implementation of surgical health programmes which match local need and build on existing resources. ${ }^{5}$ Although knowledge of needs and resources only form part of the information on which policy makers base decisions, better health service planning decisions could be made with better access to knowledge ${ }^{67}$ Ideally, there needs to be a shift in balance towards more evidence-based policy while acknowledging competing health system demands, such as HIV, tuberculosis and pandemics such as COVID19, which stopped all non-essential surgical services in South Africa for the majority of $2020 .^{8}$

Knowledge gaps must be better delineated, within a contextually relevant agenda, to facilitate the formulation of health policies and their translation into programmes that improve surgical service delivery. ${ }^{9} \mathrm{Up}$ to now, most of the strategies for African surgical care have been driven by high-income countries (HICs), with leadership from low-income and middle-income countries (LMICs) less prominent. ${ }^{10}$ For SSA nations to strengthen their surgical systems, we must use evidence-based solutions, derived from strong local contextual knowledge. The first step towards achieving this is identifying a locally agreed vision, which is informed by and informs the strategic priorities of governments; further the dependencies for achieving that vision and the knowledge needed to achieve it must be identified. Second, collaborative African networks are needed to strengthen regional research capacity to ensure that the knowledge gaps, once filled, are translated into coordinated initiatives aimed at supporting broader efforts to enhance and scale up surgical healthcare services. $^{11}$

Sixteen Southern African countries are members of the Southern African Development Community (SADC), a regional intergovernmental entity founded to promote equitable and sustainable economic growth and socioeconomic development in the region and encourage political cooperation. ${ }^{12}$ In November 2018, SADC health ministers and senior officials endorsed a resolution to prioritise surgical healthcare, ${ }^{13}$ which recognised the need for national surgical, obstetric and anaesthesia plans (NSOAPs) to facilitate this prioritisation. These countries have acknowledged that surgery should be considered an essential component of universal health coverage (UHC). To build on the 2018 SADC resolution, surgical, obstetric and anaesthesia task force members from six of the SADC countries (Botswana, Malawi, Namibia, South Africa, Zambia and Zimbabwe) and other key stakeholders were invited to be a part of the AfroSurg Collaborative (AfroSurg). These six countries are geographically and economically linked with high inter-regional migration of surgical providers and patients. While they have distinct surgical health systems, each of them has made strong commitments to the goal of improving equitable access to surgical care including developing NSOAPs.

\section{APPROACH}

\section{Inaugural conference}

The AfroSurg network was established at its inaugural conference held on 16-17 January 2020, at Stellenbosch University in Cape Town, South Africa. At the conference, a theory of change (ToC) workshop was held with participants to agree on a vision for improving surgical care in the region and identify policy and service delivery knowledge needs. All AfroSurg members participated in the workshop. The majority of the 38 participants were established leaders of surgery, anaesthesia, and obstetric research and clinical care in the six SADC countries. Additionally, three UK and six South African global health specialists served on the organising and facilitation team.

The long-term aim of our network was to be a collaborative platform to improve equitable access to quality surgical healthcare in the SADC countries. In order to achieve this aim, the objective of the ToC was to identify knowledge needs essential to improve surgical policy and service delivery in the region.

\section{THEORY OF CHANGE}

The ToC methodology was developed by Weiss in 1995 as a theory-based evaluation framework to describe how a prespecified long-term outcome can be achieved through a logical sequence of preconditions. ${ }^{14}{ }^{15}$ Explicit attention is given to links between inputs, mechanisms of change, outputs and outcomes, and regarding external factors. The ToC framework has not previously been used in the context of global surgery but has been shown to be an effective method of identifying priorities to inform the implementation of health policies in LMICs. ${ }^{16-18}$ The framework is constructed using a backward-mapping approach, starting with the long-term outcome (the vision statement) and subsequently plotting the proximate needs or 'elements' required to achieve these and their more distal dependencies (see online supplemental appendix 2 for definitions of the ToC terminology). ${ }^{19}$

\section{IDENTIFYING A VISION STATEMENT}

During the workshop, the participants were orientated to the ToC methodology and randomly divided into four groups of 8-10 people. The groups worked through their tasks and then summarised their findings to all participants for broader discussion and consensus. The first task was to develop an AfroSurg vision statement to reflect the group's focus on improving equitable access to safe 
and timely surgical care across the respective countries, thereby defining the network's future aims. The agreed vision statement of Afrosurg was 'An African-led, regional network to enable evidence-based, context-specific, safe surgical care, which is accessible, timely, and affordable for all, capturing the spirit of Ubuntu.'

\section{IDENTIFYING KNOWLEDGE NEEDS}

The next task was to identify service delivery and policy elements required to achieve the vision, where service delivery is concerned with elements needed to provide surgical healthcare, and policy refers to rules and mandates required to enable better provision of surgical healthcare. Starting with service delivery, each of the four groups discussed elements that embodied the AfroSurg vision statement before consensus was achieved on the four priority service elements. Each group was then assigned one of the main elements to identify dependencies required in order to achieve the element; these were discussed in plenary and modified through consensus. Finally, groups were reconvened to draw from these dependencies and to identify the knowledge needed to inform them and thus achieve each element. The same process was repeated for policy.

The ToC process was depicted by mapping all elements, their dependencies and knowledge needed to ensure equitable access to quality surgical healthcare in the SADC region. As customary for a ToC framework, the schematic gave direction for the research and critical analysis needed to achieve the vision and, in doing so, demonstrated how providing knowledge would be essential to accomplish this. After the workshop, the writing group (DSB, MLO, KC and JD) further analysed and refined the elements, dependencies and knowledge needs, to strengthen and enhance clarity. On completion of the primary diagram, the schematic representation of the ToC was shared and subsequently reviewed by all participants. Participant feedback and comments were considered, and adjustments were made before creating the final diagram.

The final ToC schematic is presented in figure 1 . In order to achieve the vision, we selected the highest priority service delivery elements of information, research and sharing, quality of care, communication and access to care. We identified 37 distal dependencies and 23 knowledge needs related to these four service delivery elements. The highest priority policy elements were mandatory data sets and surgical workforce followed by defined packages of care and stakeholder input. Twenty-four distal dependencies and 22 knowledge needs were identified for the policy elements. These are shown in tables 1 and 2.

\section{PRIORITISING KNOWLEDGE NEEDS}

In order to prioritise the knowledge needs identified during the ToC exercise, an electronic Delphi exercise was conducted after the workshop with all AfroSurg members. The writing group and organising/facilitation team did not participate in the Delphi exercise. All elements and their knowledge needs-for both policy and service delivery-elicited during the ToC exercise were presented to the group in the Delphi survey. The participants were asked to anonymously rank the knowledge needs from one to five on a Likert scale. A percentage score was calculated by dividing the total achieved score for each knowledge need by the maximum score that could be achieved, allowing us to rank the top 10 knowledge needs.

Of the 30 ToC participants invited to complete the Delphi exercise, 27 (90\%) responded. The top 10 knowledge needs identified by Afrosurg collaborators are shown in online supplemental appendix 3; the top 5 (table 3) were (1) mapping of available surgical services, resources and providers; (2) quantifying the burden of surgical disease; (3) identifying the appropriate number of trainees; (4) identifying the type of information that should be collected to inform service planning; and (5) identifying effective strategies to encourage geographical retention of practitioners. Four of the top five prioritised knowledge needs were policy-related, and one was related to service delivery (see table 3 ).

\section{REFLECTIONS}

Using a ToC approach is novel in global surgery. The lack of access to quality surgical care in the SADC region is a multifactorial issue, and the ToC approach is ideal to explore this topic because it allowed the group to acknowledge and then to focus on the service delivery and political processes that underlie health system change. Although others have worked to develop consensus to ultimately benefit surgical care, previous stakeholder meetings have a priori aimed to identify research priorities. ${ }^{30}$ The ToC approach starts with a participatory process to agree on a common goal which allowed us to collectively construct a vision statement prior to defining priorities and their dependencies in a more structured manner. The main drawback with the use of the ToC was the lack of participant familiarity with the process. However, the initial orientation session to the process and facilitation provided by the senior author (JID) mitigated this. Our aim was not to identify empirical research questions per se, but rather to show where knowledge is lacking which could be filled by conducting empirical research studies or, for example, audits. We are not aware of previous efforts to explicitly link knowledge needs to policy or service delivery. Increasing knowledge through empirical research or practically oriented audit facilitates improved policy and service delivery, which are essential to achieving UHC for surgery.

The AfroSurg workshop was done with, and led by, surgical providers and stakeholders from six different SADC countries who used their extensive knowledge of the setting to come up with multiple knowledge needs to improve policy and service delivery in the region. This differs from the approach of much global surgery research 

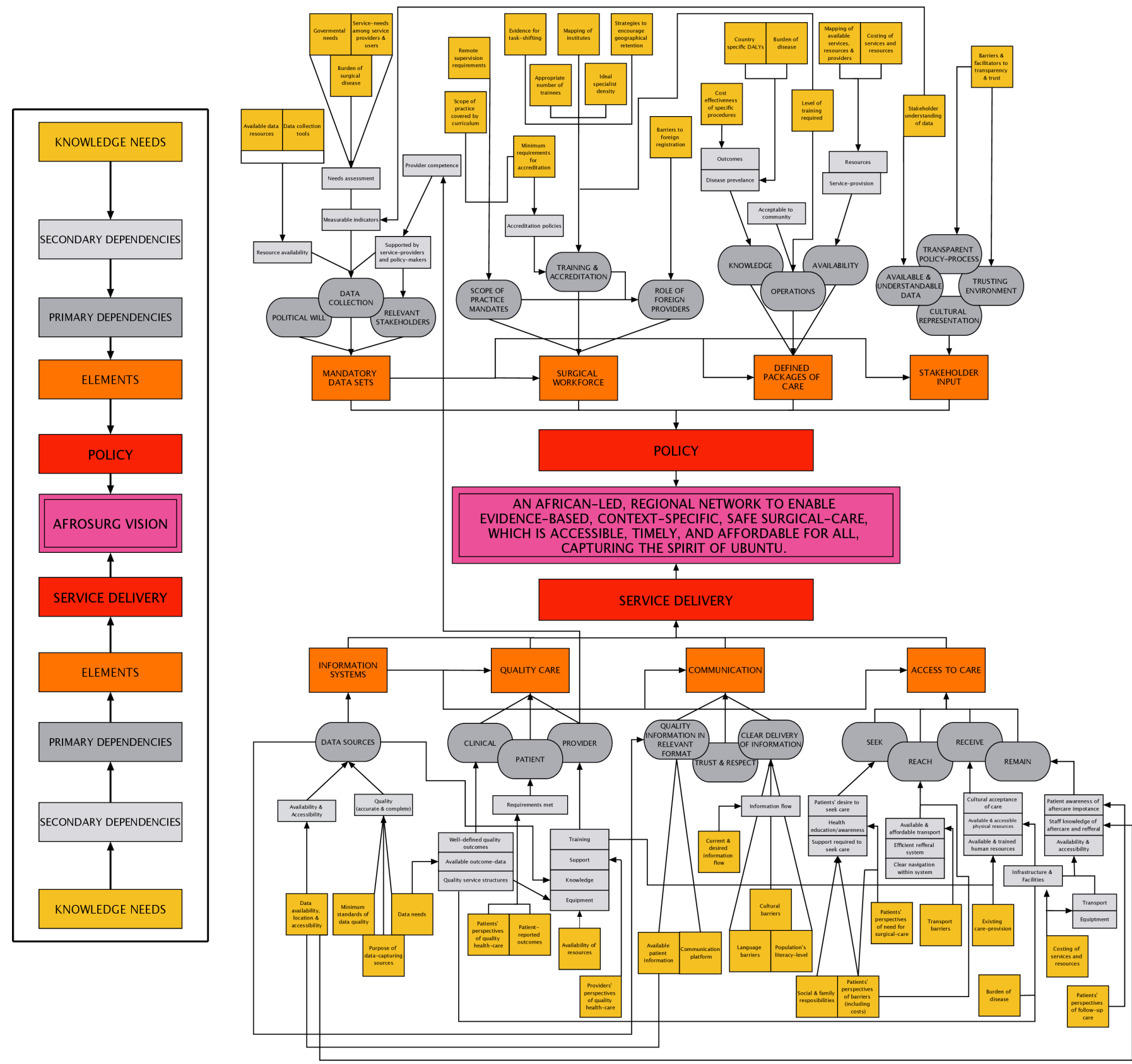

Figure 1 Depicts the long-term vision statement (pink). Policy and service delivery are positioned on either side of the vision statement along with their respective elements (orange), dependencies (grey) and knowledge needs (yellow). Notably, although the order in which the workshop was conducted was from the central to the peripheral aspect, the arrows on the figure direct one from the peripheral to the central aspect according to the order in which the steps would be carried out in practice. Hence, the figure depicts the backward mapping of the ToC methodology. The policy and service delivery side of the ToC are shown separately in the online supplemental appendices and tables 1 and 2 contain expanded information on each knowledge need. ToC, theory of change.

in the region, which has been performed or directed by HICs actors with providers or researchers from LMICs participating, but rarely truly leading. ${ }^{21} 22$ To ensure that time spent in acquiring knowledge is invested well and in a way that will inform strategy, reform approaches must be based on and driven by context-sensitive understandings of surgical systems and embedded in local culture. ${ }^{1123}$

To fulfil the vision of the AfroSurg network, the identified knowledge needs must now be addressed. The top two knowledge needs were mapping of available services, resources, and providers and quantifying the burden of surgical disease. Knowledge of supply (here referring to as available services, resources and providers) and demand (here referring to burden of disease) are essential for planning healthcare systems, but these are not well delineated enough in the region to allow this. While some investigators have aimed to ascertain surgical capacity at facilities ${ }^{24}$ and others have aimed to estimate disease burden, ${ }^{25}{ }^{26}$ attendees at the meeting acknowledged that these high-level research findings are not 
Table 1 Knowledge needs-service delivery

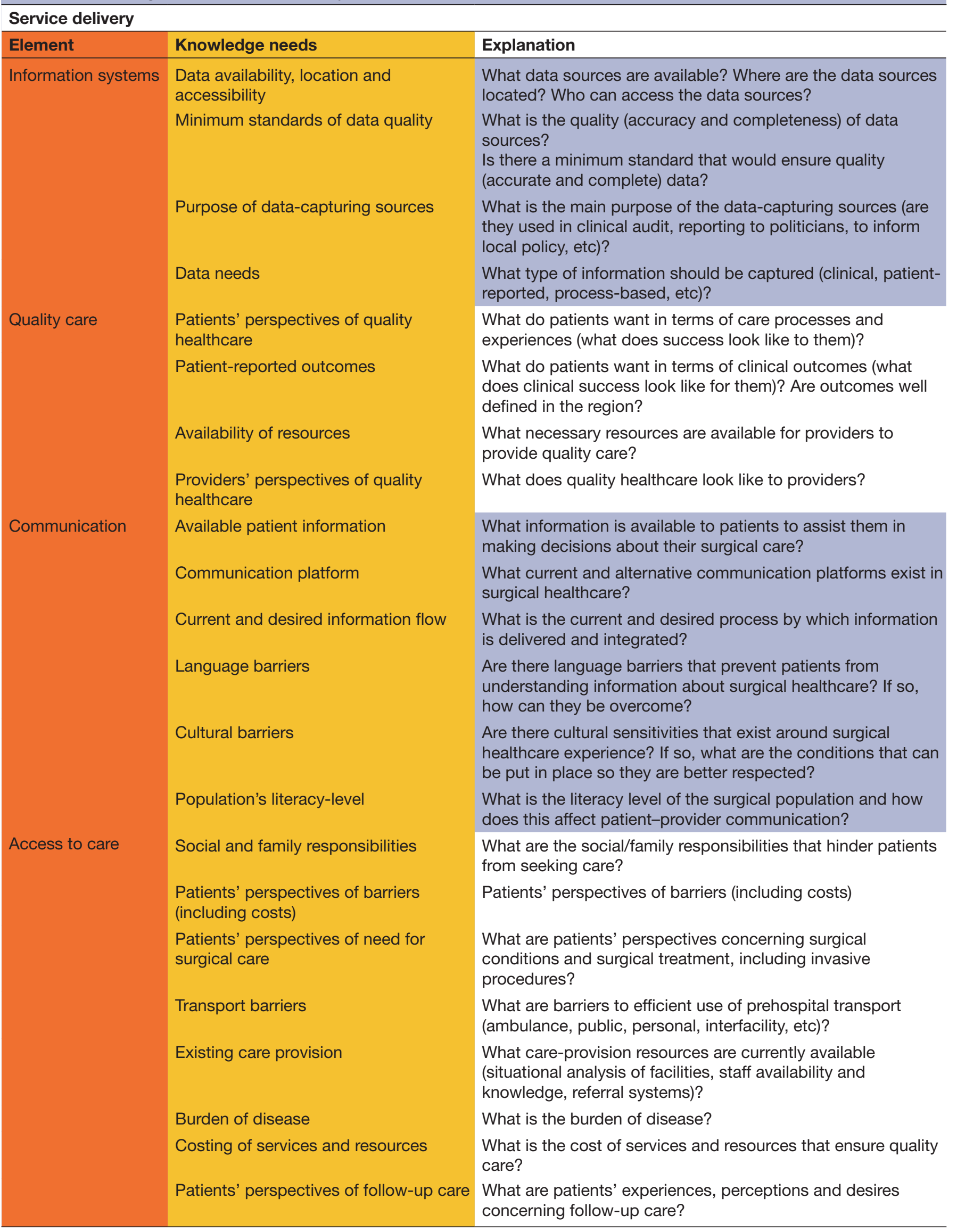


Table 2 Knowledge needs-policy

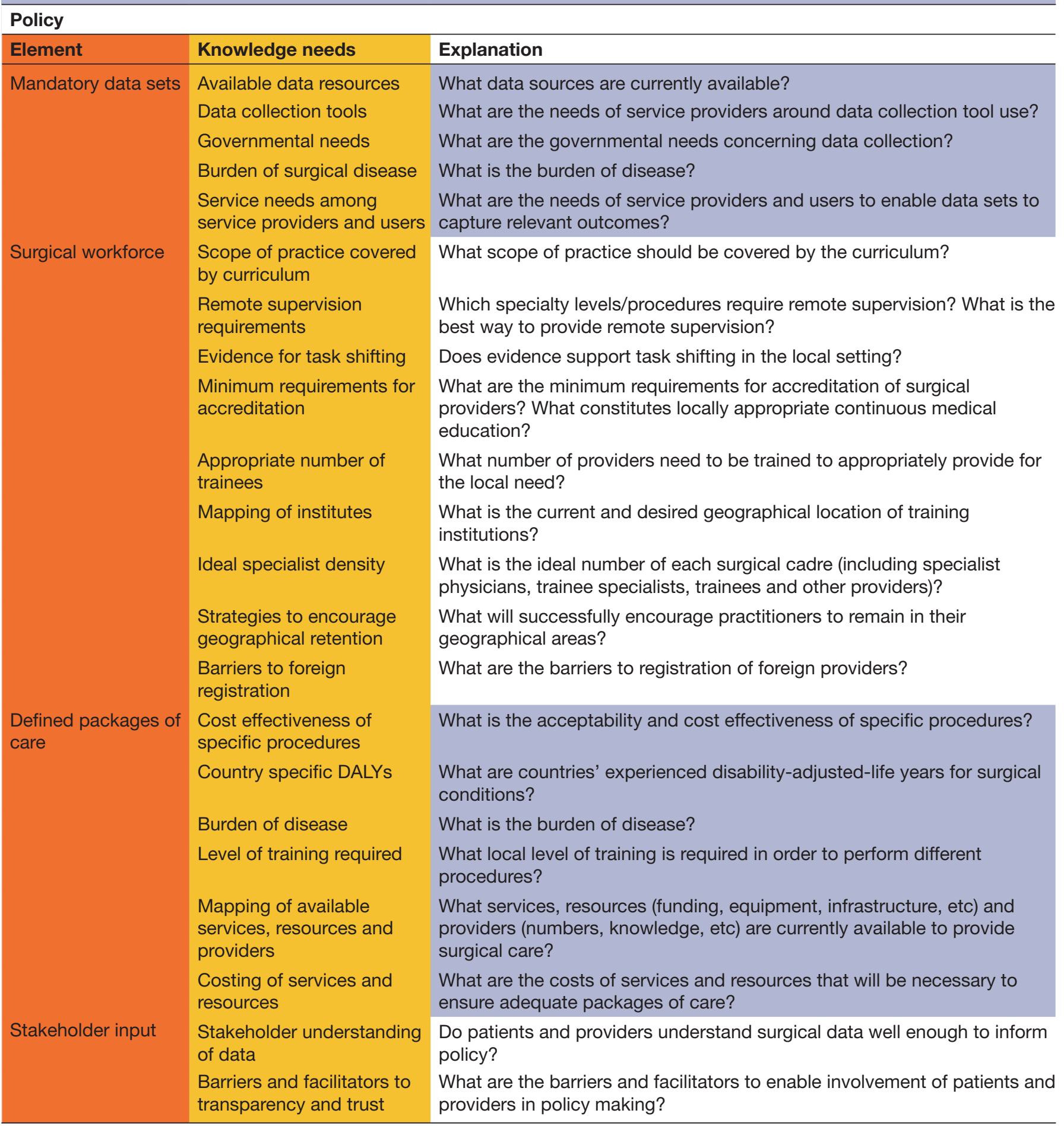

granular enough to improve surgical care at the local level. Wide-scale use of tools at facilities can help to provide knowledge on readiness or capacity to provide surgical care. Examples include the WHO Service Availability and Readiness Assessment survey, Service Provision Assessment and the WHO Surgical Situational Analysis Tool. ${ }^{27-29}$ These should ideally be used at the national level to urgently assess supply. In addition, the pooling of data at the regional level could help develop a large-scale data warehouse to facilitate use of advanced data-science tools, enabling forecasting, benchmarking and actionable insights.

Ascertaining information on the burden of surgical disease is more challenging. In health systems where financial and access barriers are minimal, the prevalence of conditions treated at health facilities closely matches the prevalence in the population. ${ }^{30}$ However, when care is unaffordable or are when patients are unaware of available services, ${ }^{1}$ such as in many African countries, ${ }^{31} 32$ the health facility disease burden may underestimate population prevalence. Disease 
Table 3 Top five knowledge needs to improve surgical care in southern Africa

\begin{tabular}{|c|c|c|c|c|}
\hline Explanation & Knowledge need & Element & Percentage score & Average score \\
\hline $\begin{array}{l}\text { What services, resources (funding, } \\
\text { equipment, infrastructure, etc) and } \\
\text { providers (numbers, knowledge, etc) are } \\
\text { currently available to provide surgical } \\
\text { care? }\end{array}$ & $\begin{array}{l}\text { Mapping of available } \\
\text { services, resources and } \\
\text { providers }\end{array}$ & $\begin{array}{l}\text { Defined packages } \\
\text { of care }^{*}\end{array}$ & $87.2 \%$ & 4.36 \\
\hline What is the burden of disease? & $\begin{array}{l}\text { Burden of surgical } \\
\text { disease }\end{array}$ & $\begin{array}{l}\text { Mandatory data } \\
\text { sets }^{*}\end{array}$ & $86.9 \%$ & 4.35 \\
\hline $\begin{array}{l}\text { What number of providers need to be } \\
\text { trained to appropriately provide for the } \\
\text { local need? }\end{array}$ & $\begin{array}{l}\text { Appropriate number of } \\
\text { trainees }\end{array}$ & $\begin{array}{l}\text { Surgical } \\
\text { workforce* }^{*}\end{array}$ & $86.4 \%$ & 4.32 \\
\hline $\begin{array}{l}\text { What type of information should be } \\
\text { captured (clinical, patient-reported, } \\
\text { process-based, etc)? }\end{array}$ & Data needs & $\begin{array}{l}\text { Information } \\
\text { systems }\end{array}$ & $85.9 \%$ & 4.30 \\
\hline $\begin{array}{l}\text { What will successfully encourage } \\
\text { practitioners to remain in their } \\
\text { geographical areas? }\end{array}$ & $\begin{array}{l}\text { Strategies to encourage } \\
\text { geographical retention }\end{array}$ & $\begin{array}{l}\text { Surgical } \\
\text { workforce* }^{*}\end{array}$ & $85.6 \%$ & 4.28 \\
\hline
\end{tabular}

*Policy.

†Service delivery.

burden modelling can be inaccurate, ${ }^{33}$ and data collection from household surveys using validated tools may be needed to obtain accurate estimates of the burden of surgical conditions in SADC countries.

Estimating the number of trainees needed to deliver surgical services to match the burden of disease was the third highest priority. Without accurate data on the true disease burden, this will be a challenging knowledge need to fill. Knowledge of effective incentives to encourage practitioners to remain in their geographical areas and prevent 'brain drain' was our fifth priority and an issue that affects many African countries. ${ }^{34}$ Appraisal of initiatives that have been implemented elsewhere ${ }^{35}$ (ie, use of monetary incentives, binding contracts or training programmes that are delivered in key areas of need) can inform consensus on the best solutions to minimise 'push' and 'pull' factors for physician/surgeon movement in SADC countries.

Of the top five knowledge needs, four were policy-related, suggesting a dearth of much-needed information to develop evidenced-based effective surgical policies in the region. The only service delivery knowledge need prioritised among the top five at our meeting was to define service planning information. These results can also inform health system planning at the local and national levels. Importantly, all indicators that will be chosen cannot be difficult to collect. There was an acknowledgement during the workshop that although robust data collection is needed, indicators should be easy to obtain (eg, those collected already as part of routine clinical care) so as not to overwhelm existing scarce human resources.

Even though the need for improving access to safe, affordable surgical care has been previously articulated, there has been a lack of political priority to improve this. ${ }^{6}$ Shiffman and Smith has described four key components required to achieve political priority in global health: actor power (the strength of individuals and organisations concerned with the issue), ideas (the ways in which those involved with the issue understand and portray it), political contexts (the environments in which actors operate) and issue characteristics (features of the problem). ${ }^{7}$ AfroSurg has made progress to ensure that these four key components are met in our region. In our ToC, the need to collect more data to inform issue characteristics was clearly articulated, both for health systems and policy. Our group stopped short of defining indicators to understand the size of the problem and to monitor progress, given there is an ongoing global initiative to do this. ${ }^{3637}$ Moreover, AfroSurg, which brings together actors from six different African countries, with support rather than leadership from HICs, aims to improve surgical care in the region with local actor power. Political contexts in the SADC region are already favourable with many countries having embarked on the NSOAP process. The ideas element of Shiffman and Smith's framework states that a clear message on the problem is needed. AfroSurg and the ToC workshop were initial steps towards achieving strong internal framing around the needs to improve access to quality surgical care and practicalities needed to enable this change, emanating from regional key actors.

\section{NEXT STEPS}

AfroSurg is a small network, but the participants at the first meeting had a broad range of backgrounds related to surgical care from providers, policy makers and researchers. The network fulfils several of Shiffman and Smith's requirements to improve political priority, but not all. In future meetings, we plan to identify where some knowledge needs have been filled, how we can prioritise data collection to fill remaining knowledge needs and discuss at what intervals to conduct audits to ascertain whether remaining knowledge needs have been filled. 
Many of the AfroSurg stakeholders are leaders in service delivery and policymaking in their respective countries and will communicate the findings from this workshop to their country's surgical stakeholders. In addition, we plan to secure funding to meet annually and update the ToC after 5 years, after which many of the knowledge gaps should be filled and new evidence generated. We also recognise the need to invite more local interested stakeholders such as political actors, civil society organisations and service users to our meetings in order create a seamless line connecting the community to services and policy to ensure that we are working towards a shared agenda.

\section{CONCLUSION}

AfroSurg, launched in January 2020, is a new Southern African network consisting of key stakeholders from six countries. During a 2-day workshop, a joint vision statement for the network was created and a ToC approach was used to identify 45 knowledge needs in policy and service delivery, which should inform future research priorities in order to improve surgical care in the region. An electronic Delphi revealed that the top knowledge need is mapping of available surgical services, resources and providers. This work fulfils the critical need for a transnational African-based collaboration in global surgery. The findings from this workshop provide a vision and roadmap to drive locally led research and create a collaborative network for implementing research and interventions. Even though the network is regional, the findings could be transferable and be used to inform policy and research priorities for surgical care in other parts of SSA. Additionally, the ToC approach can be used in other settings or areas to come up with context-specific priorities to improve healthcare.

\section{Author affiliations}

${ }^{1}$ Faculty of Medicine and Health Sciences, Stellenbosch University, Cape Town, South Africa

${ }^{2}$ Institute of Applied Health Research, University of Birmingham, Birmingham, UK ${ }^{3}$ Faculty of Health Sciences, University of Botswana, Gaborone, Botswana ${ }^{4}$ Department of Anaesthesia, University of Botswana, Gaborone, Botswana ${ }^{5}$ Department of Surgery, Princess Marina Hospital, Gaborone, Botswana ${ }^{6}$ Department of Surgery, University of Botswana, Gabarone, Botswana ${ }^{7}$ Department of Medical Education, University of Botswana, Gaborone, Botswana ${ }^{8}$ Department of Surgery, University of Namibia, Windhoek, Namibia

${ }^{9}$ Department of Surgery, Onandjokwe Lutheran Hospital, Oniipa, Namibia

${ }^{10}$ University of Namibia, Windhoek, Namibia

${ }^{11}$ Anaesthesiologists Society of Namibia, Windhoek, Namibia

${ }^{12}$ Department of Anaesthesia and Perioperative Medicine, Faculty of Health Sciences, University of Cape Town, Observatory, South Africa

${ }^{13}$ Faculty of Health Sciences, University of Cape Town, Observatory, South Africa

${ }^{14}$ Anaesthesiology and Critical Care, Faculty of Medicine and Health Sciences, Stellenbosch University, Cape Town, South Africa

${ }^{15}$ Department of Obstetrics and Gynaecology, Faculty of Medicine and Health

Sciences, Stellenbosch University, Cape Town, South Africa

${ }^{16}$ Department of Anthropology, Humanities Faculty, University of Cape Town, Cape Town, South Africa

${ }^{17}$ Centre for Global Surgery, Faculty of Medicine and Health Sciences, Stellenbosch University, Cape Town, South Africa

${ }^{18}$ Global Surgery Division, Department of Surgery, Faculty of Health Sciences, University of Cape Town, Cape Town, South Africa
${ }^{19}$ Executive Management, Groote Schuur Hospital, Department of Public Health and Familiy Medicine, University of Cape Town, Cape Town, South Africa

${ }^{20}$ Harvard Medical School, Boston, Massachusetts, USA

${ }^{21}$ Department of Surgery, College of Health Sciences, University of Zimbabwe, Harare, Zimbabwe

${ }^{22}$ Division of Anaesthesia, Parirenyatwa Hospital, Harare, Zimbabwe

${ }^{23}$ Aberdeen Centre for Health Data Science, Institute of Applied Health Sciences, School of Medicine, Medical Sciences and Nutrition, University of Aberdeen, Aberdeen, Scotland, UK

${ }^{24}$ Medical Research Council/Wits University Rural Public Health and Health Transitions Research Unit, Faculty of Health Sciences, School of Public Health, University of the Witwatersrand, Johannesburg, South Africa

Twitter Moneimang Makgasa @MMakgasa, Akutu Munyika @Ak Munyika, Theresia Shivera @AnaesthesiaNam, Bruce Biccard @brucebiccard, Shrikant Peters @ShrikantPeters, Ché L Reddy @CheLenReddy, Lucia D'Ambruoso @luciadambruoso, Kathryn Chu @kathryn_chu_sa and Justine I Davies @drjackoids

Acknowledgements We would like to acknowledge all the individuals who participated in the theory of change workshop.

Contributors The writing group, DSB, MLO, KC and JID, constructed the manuscript, created the tables and figures, and reported the findings in the practice paper. All authors took part in the theory of change workshop and identified knowledge needs which formed the basis of the practice paper.

Funding Funding for the workshop was provided by the UK Academy of Medical Sciences, Global Challenges Research Fund Networking Grant. The funding did not include any studies or papers that were based on the workshop findings.

Competing interests None declared.

\section{Patient consent for publication Not required.}

Ethics approval Consent was obtained from all the participants prior to participating in the theory of change workshop as well as the subsequent Delphi survey. All participants were academics, policy makers or healthcare professionals acting in their professional capacity. They gave consent for findings to be published and most are authors on the manuscript.

Provenance and peer review Not commissioned; externally peer reviewed.

Data availability statement All data relevant to the study are included in the article or uploaded as supplementary information.

Supplemental material This content has been supplied by the author(s). It has not been vetted by BMJ Publishing Group Limited (BMJ) and may not have been peer-reviewed. Any opinions or recommendations discussed are solely those of the author(s) and are not endorsed by BMJ. BMJ disclaims all liability and responsibility arising from any reliance placed on the content. Where the content includes any translated material, BMJ does not warrant the accuracy and reliability of the translations (including but not limited to local regulations, clinical guidelines, terminology, drug names and drug dosages), and is not responsible for any error and/or omissions arising from translation and adaptation or otherwise.

Open access This is an open access article distributed in accordance with the Creative Commons Attribution Non Commercial (CC BY-NC 4.0) license, which permits others to distribute, remix, adapt, build upon this work non-commercially, and license their derivative works on different terms, provided the original work is properly cited, appropriate credit is given, any changes made indicated, and the use is non-commercial. See: http://creativecommons.org/licenses/by-nc/4.0/.

\section{ORCID iDs}

Maria Lisa Odland http://orcid.org/0000-0003-4340-7145

Margaret Tarpley http://orcid.org/0000-0002-5803-9472

Akutu Munyika http://orcid.org/0000-0002-5736-6586

Bruce Biccard http://orcid.org/0000-0001-5872-8369

Regan Boden http://orcid.org/0000-0002-8650-161X

Ché L Reddy http://orcid.org/0000-0002-8800-7359

Lucia D'Ambruoso http://orcid.org/0000-0002-8505-3368

\section{REFERENCES}

1 Meara JG, Leather AJM, Hagander L, et al. Global surgery 2030: evidence and solutions for achieving health, welfare, and economic development. Int J Obstet Anesth 2016;25:75-8. 
2 Jumbam DT, Reddy CL, Makasa E, et al. Investing in surgery: a value proposition for African leaders. Lancet 2020;396:7-9.

3 Biccard BM, Madiba TE, Kluyts H-L, et al. Perioperative patient outcomes in the African surgical outcomes study: a 7-day prospective observational cohort study. Lancet 2018;391:1589-98.

4 Bickler SN, Weiser TG, Kassebaum N. Global burden of surgical conditions. In: Debas HT, Donkor P, Gawande A, et al, eds. Essential surgery: disease control priorities, 3rd edn (volume 1). Washington (DC): The International Bank for Reconstruction and Development / The World Bank, 2015.

5 Reddy CL, Makasa EM, Biccard B, et al. Surgery as a component of universal healthcare: where is South Africa? S Afr Med J 2019;109:624-5.

6 Shawar YR, Shiffman J, Spiegel DA. Generation of political priority for global surgery: a qualitative policy analysis. Lancet Glob Health 2015;3:e487-95.

7 Shiffman J, Smith S. Generation of political priority for global health initiatives: a framework and case study of maternal mortality. Lancet 2007;370:1370-9.

8 Chu KM, Smith M, Steyn E, et al. Changes in surgical practice in 85 South African hospitals during COVID-19 hard lockdown. S Afr Med J 2020;110:916-9.

9 Makasa EM. Universal access to surgical care and sustainable development in Sub-Saharan Africa: a case for surgical systems research comment on "Global Surgery - Informing National Strategies for Scaling Up Surgery in Sub-Saharan Africa". Int $J$ Health Policy Manag 2019;8:58-60.

10 Ng-Kamstra JS, Greenberg SLM, Abdullah F, et al. Global surgery 2030: a roadmap for high income country actors. BMJ Glob Health 2016;1:e000011.

11 Gajewski J, Bijlmakers L, Brugha R. Global surgery - informing national strategies for scaling up surgery in Sub-Saharan Africa. Int $J$ Health Policy Manag 2018;7:481-4.

12 Southern African Development Community (SADC). Mission statement, 2021. Available: https://www.sadc.int/about-sadc/ overview/sadc-mission/

13 Southern African Development Community Secretariat. Joint meeting of SADC ministers of health, 2018. Available: https://www. sadc.int/news-events/news/joint-meeting-sadc-senior-officialshealth-and-those-responsible-hiv-and-aids-convenes-discusspublic-health-issues/

14 Weiss $\mathrm{CH}$. Nothing as practical as good theory: exploring TheoryBased evaluation for comprehensive community initiatives for children and families, new approaches to evaluating community initiatives, 2021. Available: https://www.semanticscholar.org/paper/ Nothing-as-Practical-as-Good-Theory-\%3A-Exploring-for-Weiss/ ed98a1ac4b7b54ef4854b7b7a802db7b3e46ae02?p2df

15 Vogel I. Review of the use of 'Theory of Change' in international development.' UK Department of International Development, 2012. Available: https://assets.publishing.service.gov.uk/media/57a08a5d ed915d3cfd00071a/DFID_ToC_Review_VogelV7.pdf

16 Paina L, Wilkinson A, Tetui M, et al. Using theories of change to inform implementation of health systems research and innovation: experiences of future health systems Consortium partners in Bangladesh, India and Uganda. Health Res Policy Syst 2017;15:109.

17 Yearwood AC. Applying a logical theory of change for strengthening research uptake in policy: a case study of the evidence informed decision making network of the Caribbean. Rev Panam Salud Publica 2018;42:e91.

18 Breuer E, De Silva M, Lund C. Theory of change for complex mental health interventions: 10 lessons from the programme for improving mental healthcare. Glob Ment Health 2018;5:e24.
19 Anderson AA. The community builder's approach to theory of change: a practical guide to theory development. The Aspen Institute Roundtable on Community Change, New York, NY, 2021. Available: https://www.theoryofchange.org/pdf/TOC_fac_guide.pdf

20 National Institute for Health Research Global Health Research Unit on Global Surgery. Prioritizing research for patients requiring surgery in low- and middle-income countries. Br J Surg 2019;106:e113-20.

21 Baison GN, Maine R, Chu K, et al. Authorship equity in global surgery research from low- and middle-income countries (LMICs). Annals of Global Health 2014;80:240.

22 Hedt-Gauthier BL, Jeufack HM, Neufeld NH, et al. Stuck in the middle: a systematic review of authorship in collaborative health research in Africa, 2014-2016. BMJ Glob Health 2019;4:e001853.

23 Nyaaba GN, Stronks K, de-Graft Aikins A, et al. Tracing Africa's progress towards implementing the non-communicable diseases global action plan 2013-2020: a synthesis of who country profile reports. BMC Public Health 2017;17:297.

24 Ouma PO, Maina J, Thuranira PN, et al. Access to emergency hospital care provided by the public sector in sub-Saharan Africa in 2015: a geocoded inventory and spatial analysis. Lancet Glob Health 2018:6:e342-50.

25 Zafar SN, Canner JK, Nagarajan N, et al. Road traffic injuries: crosssectional cluster randomized countrywide population data from 4 low-income countries. Int J Surg 2018;52:237-42.

26 Groen RS, Samai M, Stewart K-A, et al. Untreated surgical conditions in Sierra Leone: a cluster randomised, cross-sectional, countrywide survey. Lancet 2012;380:1082-7.

27 World Health Organization. Service availability and readiness assessment (SARA), 2015. Available: https://apps.who.int/iris/ bitstream/handle/10665/149025/WHO_HIS_HSI_2014.5_eng. pdf;jsessionid=7CA7E366F9FA9A26C4A6AB983B91687D? sequence $=1$

28 The DHS Program. SPA overview, 2021. Available: https:// dhsprogram.com/methodology/Survey-Types/SPA.cfm

29 World Health Organization. Who surgical assessment tool, 2021. Available: https://www.who.int/surgery/publications/s15986e.pdf? ua $=1$

30 Hider $\mathrm{P}$, Wilson L, Rose J, et al. The role of facility-based surgical services in addressing the National burden of disease in New Zealand: an index of surgical incidence based on country-specific disease prevalence. Lancet 2015;385 Suppl 2:S25.

31 Odland ML, Whitaker J, Nepogodiev D, et al. Identifying, prioritizing and visually mapping barriers to injury care in Rwanda: a multidisciplinary Stakeholder exercise. World J Surg 2020;44:2903-18.

32 Fraser A, Newberry Le Vay J, Byass P, et al. Time-critical conditions: assessment of burden and access to care using verbal autopsy in Agincourt, South Africa. BMJ Glob Health 2020;5:e002289.

33 Institute for Health Metrics and Evaluation. IHME measuring what matters, 2021. Available: http://www.healthdata.org/

34 Adovor E, Czaika M, Docquier F, et al. Medical brain drain: how many, where and why? J Health Econ 2021;76:102409.

35 Gajewski J, Mweemba C, Cheelo M, et al. Non-Physician clinicians in rural Africa: lessons from the medical Licentiate programme in Zambia. Hum Resour Health 2017;15:53.

36 Odland ML, Nepogodiev D, Morton D, et al. Identifying a basket of surgical procedures to standardize global surgical metrics: an international Delphi study. Ann Surg 2020. doi:10.1097/ SLA.0000000000004611. [Epub ahead of print: 17 Nov 2020] (published Online First: 2020/11/21).

37 Holmer $\mathrm{H}$, Bekele A, Hagander L, et al. Evaluating the collection, comparability and findings of six global surgery indicators. Br J Surg 2019;106:e138-50. 